\title{
6
}

\section{METÁFORA E INTEGRAÇÃO CONCEPTUAL EM POST MULTIMODAL: GOVERNO BRASILEIRO NA PANDEMIA DA COVID-19}

\author{
METAPHOR AND CONCEPTUAL BLENDING IN \\ MULTIMODAL POST: BRAZILIAN GOVERNMENT IN THE \\ COVID-19 PANDEMIC
}

\author{
Naira Velozo 1 \\ Universidade do Estado do Rio de Janeiro \\ Sandra Bernardo ${ }^{2}$ \\ Universidade do Estado do Rio de Janeiro \\ Wellington Almeida ${ }^{3}$ \\ Universidade Federal do Rio de Janeiro
}

\begin{abstract}
Resumo: Análise indutiva, com abordagem qualitativa, de dois posts multimodais da página virtual Uerj da depressão (UDD) à luz das teorias da Metáfora Conceptual (LAKOFF; JOHNSON, 2002[1980]; FORCEVILLE, 2006) e da Integração Conceptual (FAUCONNIER; TURNER, 2002), a fim de verificar como essas teorias podem descrever, conjuntamente, a significação do gênero post e identificar estruturas e processos cognitivos subjacentes à construção de sentidos acerca da pandemia da COVID-19 nos objetos analisados. Os posts foram selecionados de um corpus constituído por textos multimodais publicados na UDD em março, junho e julho de 2020, segundo dois critérios: semelhança temática e composição textual distinta. Os resultados da análise (i) reforçam a ideia de complementaridade entre as teorias adotadas; (ii) corroboram postulados de Forceville (2006) quanto à classificação de metáforas monomodais e multimodais; e (iii) evidenciam, na conceptualização de ambas as postagens, a ativação dos mesmos frames estruturantes dos inputs e conhecimentos básicos nos espaços genéricos (PESSOA, PAPEL, OBJETO e PARTE DO CORPO), além de processos cognitivos comuns, projeções PAPEL-VALOR e ANALOGIA, comprimidas em UNICIDADE na mescla.
\end{abstract}

\footnotetext{
${ }^{1}$ Endereço eletrônico: naira_velozo@yahoo.com.br

2 Endereço eletrônico: sandrabernardo61@gmail.com

${ }^{3}$ Endereço eletrônico: wellingtonalmeida@letras.ufrj.br
} 
Palavras-Chave: Metáfora conceptual; Integração conceptual; COVID-19; Governo brasileiro; Post.

\begin{abstract}
Inductive analysis, with a qualitative approach, of two multimodal posts from the Facebook virtual page UERJ da depressão (UDD) in the light of the theories of Conceptual Metaphor (LAKOFF; JOHNSON, 2002[1980]; FORCEVILLE, 2006) and Conceptual Blending (FAUCONNIER; TURNER, 2002), in order to verify how these theories can jointly describe the meaning of the genre post and identify cognitive structures and processes that allow the construction of meanings about the COVID-19 pandemic in the analyzed objects. The posts were selected from a corpus consisting of multimodal texts published on the UDD Facebook page in March, June and July 2020, according to two criteria: thematic similarity and distinct textual composition. The results of the analysis (i) reinforce the idea of complementarity between the theories adopted; (ii) corroborate Forceville's (2006) postulates regarding the classification of monomodal and multimodal metaphors; and (iii) evidence, in the conceptualization of both posts, the activation of the same structuring frames of inputs and basic knowledge in generic spaces (PERSON, ROLE, OBJECT and PART OF THE BODY), in addition to common cognitive processes, ROLE-VALUE and ANALOGY projections, compressed in UNIQUENESS in the blend.
\end{abstract}

Keywords: Conceptual metaphor; Conceptual blending; COVID-19; Brazilian government; Post.

\title{
INTRODUÇÃO
}

No início do ano de 2020, alastrou-se, pelo Brasil, a pandemia ocasionada pela propagação do novo coronavírus. Segundo dados disponibilizados no portal de notícias G1, do Grupo Globo, em 20 de julho de $2020^{4}$, o país já ultrapassou o número de 2 milhões de habitantes infectados pelo vírus e 80 mil mortes por COVID-19; além disso, 700 mil empresas e quase 8 milhões de postos de trabalho foram fechados ${ }^{5}$, com previsão de se atingir o total de 15 milhões de pessoas desempregadas, em razão das medidas de contenção da doença somadas à política neoliberal de austeridade do Estado.

A despeito das determinações da Organização Mundial de Saúde (OMS) e do exemplo de países que adotaram medidas adequadas ao enfrentamento da pandemia, o Governo Federal brasileiro, representado pelo presidente Jair

4 Disponível em: https://g1.globo.com/bemestar/coronavirus/noticia/2020/07/20/casos-emortes-por-coronavirus-no-brasil-em-20-de-julho-segundo-consorcio-de-veiculos-deimprensa.ghtml. Acesso em: 5 jul. 2020.

5 Disponível em: https://oglobo.globo.com/economia/mais-de-700-mil-empresas-quefecharam-as-portas-nao-vao-reabrir-apos-fim-da-pandemia-24535458. Acesso em: 5 jul. 2020. 
Bolsonaro, posicionou-se contrariamente ao estado de quarentena e distanciamento social, defendendo a estratégia de imunização de rebanho como superação da crise sanitária, embora a comunidade científica só considere essa estratégia em casos de doenças para as quais já existam vacinas. Nesse contexto, optou-se por analisar posts multimodais da página Uerj da depressão (UDD) que apresentam críticas à postura do Governo diante da pandemia.

A UDD é uma página da rede social Facebook criada no final de 2010, com o objetivo inicial de expressar comentários descontraídos sobre o cotidiano da Universidade do Estado do Rio de Janeiro (UERJ). Porém, com o tempo, assuntos nacionais também passaram a ser alvo de postagens. Em 2020, a maioria dos posts da UDD relacionam-se ao quadro sanitário e político brasileiro. Duas dessas postagens foram selecionadas para análise - uma constituída de legenda e texto composto por linguagem verbal e não verbal, e outra formada por legenda e texto não verbal -, a fim de descrever, com base nas teorias da Metáfora e da Integração Conceptual (LAKOFF; JOHNSON, 2002[1980]; FORCEVILLE, 2006; FAUCONNIER; TURNER, 2002), a conceptualização das postagens e identificar estruturas e processos cognitivos que subjazem à construção de sentidos acerca do posicionamento do Governo Federal diante da pandemia da COVID-19.

Para cumprir com os objetivos do trabalho, na próxima seção, retomamse, brevemente, aspectos das teorias da Metáfora e da Integração Conceptual essenciais à análise; na segunda seção, apresenta-se a metodologia adotada; na terceira seção, analisam-se as postagens multimodais; na última, tecem-se as considerações finais; por fim, apresentam-se as referências.

\section{METÁFORA E INTEGRAÇÃO CONCEPTUAL}

Lakoff e Johnson (2002[1980]) afirmam que a metáfora não é apenas um ornamento retórico, mas "está infiltrada na vida cotidiana, não somente na linguagem, mas também no pensamento e na ação" (LAKOFF; JOHNSON, 2002[1980], p. 45). Os autores postulam que o sistema conceptual humano é 
fundamentalmente metafórico, diferenciando o conceito de 'metáfora conceptual', relacionado a habilidades cognitivas gerais (percepção, atenção, memória, categorização, habilidades linguísticas etc.), do conceito de 'expressão metafórica', compreendido como o gatilho verbal que permite a ativação da metáfora conceptual, ao defenderem que a natureza da metáfora não é estritamente linguística.

Um exemplo dessa diferença pode ser observado a partir da manchete “Ex-Ministro Sérgio Moro sobe em popularidade nas redes sociais e se aproxima do ainda líder Bolsonaro", publicada em 27 de abril de 2020 no jornal on-line O $S u l^{6}$, em que a expressão metafórica, ou gatilho, "sobe" evidencia a ativação das metáforas conceptuais STATUS SOCIAL É VERTICALIDADE e BOM É PARA CIMA/ RUIM É PARA BAIXO, construídas a partir da experiência corpórea e cultural e armazenadas na memória de longo prazo. Dessa forma, para Lakoff e Johnson (2002[1980]), as metáforas são relações estáveis e sistemáticas entre dois domínios conceptuais: o domínio-fonte, constituído de propriedades físicas e áreas relativamente concretas da experiência, e o domínio-alvo, que tende a ser mais abstrato.

Assim como a metáfora, os autores consideram a metonímia um processo cognitivo, no entanto, o mapeamento entre entidades ocorre em um mesmo domínio conceptual, no qual a entidade-veículo é selecionada para acessar a entidade-alvo, como no caso das metonímias PARTE PELO TODO, em que a parte representa o todo determinando seu aspecto focalizado.

Os domínios podem ser estruturados na forma de frames ou modelos cognitivos idealizados $(\mathrm{MCIs})^{7}$, estruturas de conhecimento armazenadas na

\footnotetext{
6 Disponível em: https://www.osul.com.br/ex-ministro-sergio-moro-sobe-em-popularidadenas-redes-sociais-e-se-aproxima-do-ainda-lider-bolsonaro/. Acesso em: 5 jul. 2020.

${ }^{7}$ Como Fauconnier e Turner (2002) utilizam a noção frame, adotou-se esse conceito na análise, em vez de MCI. Utilizou-se também o termo 'domínio' na descrição de metáforas conceptuais, uma vez que Lakoff e Johnson (2002[1980]) adotam os termos 'domínio-fonte' e 'domínioalvo'.
} 
memória de longo prazo. Frame é compreendido como esquematização de cenas da experiência. De acordo com Fillmore (2006, p. 373, tradução nossa), trata-se de um "sistema de conceitos relacionados, de tal forma que, para entender qualquer um deles, é necessário compreender toda a estrutura em que se enquadram" ${ }^{\prime 8}$. Os MCIs, por sua vez, unem a noção de frame a expectativas socioculturais, sendo compreendidos como um conjunto complexo de frames (LAKOFF, 1987). Evans e Green (2006) ressaltam que, para Lakoff, frame equivale a um tipo proposicional de $\mathrm{MCI}$, que "abrange o conhecimento sobre cenas reais, comportamentos e rotinas" (EVANS; GREEN, 2006).

Esquemas imagéticos, considerados por Lakoff (1987) um dos princípios estruturantes que compõem os MCIs, também podem operar como domíniosfonte, como o esquema CIMA-BAIXO ou VERTICALIDADE. Gibbs e Colston (2006) definem esquemas imagéticos como gestalts experienciais que emergem conforme se manipulam objetos, orienta-se espacial e temporalmente e direcionase o foco perceptual com diferentes propósitos. Os autores enfatizam que, apesar de os esquemas imagéticos derivarem de processos perceptuais e motores, não são processos sensório-motores, mas meios primários, imaginativos e nãoproposicionais, por meio dos quais se constitui ou se organiza a experiência (GIBBS; COLSTON, 2006, p. 30). Segundo Lakoff e Johnson (2002[1980]), o mapeamento metafórico é unidirecional, ou seja, o domínio-alvo é compreendido e experienciado a partir da projeção parcial de elementos do domínio-fonte, mas o inverso não ocorre.

Tendo em vista que o trabalho de Lakoff e Johnson (2002[1980]) se apoia em gatilhos verbais, Forceville $(2006,2008)$ afirma que, para validar a ideia de que as metáforas são expressas pela linguagem verbal, mas não são, necessariamente, de natureza linguística, é preciso demonstrar também suas manifestações de maneira não verbal e multimodal, por meio de sistemas de

8 By the term 'frame' I have in mind any system of concepts related in such a way that to understand any one of them you have to understand the whole structure in which it fits. 
sinalização ou de signos chamados modos, os quais indicam, independentemente ou em combinação, alvos e fontes metafóricos. Grosso modo, Forceville (2006) define modo como um sistema de signos interpretável devido a um processo de percepção específico relacionado a um dos cinco sentidos.

Dessa forma, o autor ressalta que os modos incluem sinais pictóricos, escritos ou falados, gestos, sons, música, cheiros, gostos, toque. Com base na combinação ou não desses modos na ativação de metáforas, o autor classifica as metáforas em monomodais ou multimodais. Na primeira, domínio-alvo e domínio-fonte são, exclusiva ou predominantemente, constituídos por um único modo, como as metáforas pictóricas ou visuais; enquanto, na segunda, alvo e fonte são representados, exclusiva ou predominantemente, em modos diferentes. Os trabalhos de Forceville $(2008,2017)$ sobre metáforas em propagandas revelam que muitas metáforas visuais e multimodais são do tipo OBJETO A É OBJETO B, o que corrobora o questionamento de Forceville (2006) ao princípio da unidirecionalidade da metáfora conceptual.

Enquanto, para a Teoria da Metáfora Conceptual, a construção do sentido ocorre por meio da projeção entre dois domínios conceptuais; para a Teoria da Mesclagem Conceptual, o sentido surge por meio de conexões e projeções entre, pelo menos, quatro espaços mentais ativados simultaneamente, a saber: (a) espaços-input 1 e 2, domínios de conhecimento iniciais interconectados; (b) espaço genérico, que contém informações básicas comuns aos elementos dos inputs e permite a ativação simultânea de todos os espaços e o acesso ou retorno a cada um deles a qualquer momento do processamento da informação, o que viabiliza a constante reconstrução do sentido; e (c) espaço-mescla, em que elementos dos espaços iniciais são parcialmente projetados e um novo sentido surge como estrutura emergente.

Espaços mentais são domínios cognitivos que emergem e se dissipam durante o pensamento e a fala, por meio dos quais se processam informações de forma particionada (FAUCONNIER, 1997). Embora esses espaços operem na 
memória de trabalho, são construídos parcialmente pela ativação de estruturas da memória de longo prazo, como MCIs e frames.

Além do processo de mesclagem conceptual, a construção do significado depende ainda de duas outras operações cognitivas básicas inter-relacionadas: identidade e imaginação (FAUCONNIER; TURNER, 2002, p. 6). A operação de identidade consiste em perceber equivalências e oposições entre elementos concretos ou abstratos, a fim de estabelecer relações entre eles e/ou delimitá-los. Identidade e integração não operam sem imaginação, pois, mesmo com ausência de estímulo externo, o cérebro pode produzir simulações, como ficção, sonho e cenários hipotéticos.

Conforme Forceville (2006), a construção da identidade pode ocorrer por semelhança perceptual, entre tamanho, cor, posição, postura, textura, materialidade, por exemplo; por preenchimento de um slot esquemático inesperadamente, ou seja, inserção de algo em contexto não natural ou convencional, desvios em relação a gestalts ou esquemas típicos; ou por sugestão simultânea, duas coisas sinalizadas em modos diferentes, por exemplo, "um beijo acompanhado por som de um acidente de carro, de um aspirador de pó ou de um barulho de correntes, para indicar mapeamentos metafóricos de desastre, rotina doméstica enfadonha e prisão, respectivamente." (FORCEVILLE, 2006, p. 13, tradução nossa) .

Além da metáfora e da metonímia, outras relações conceptuais, denominadas relações vitais por Fauconnier e Turner (2002), atuam rotineiramente na formação da estrutura emergente do espaço-mescla, ou seja, na construção de novos sentidos. Nas análises propostas neste trabalho, destacam-se as seguintes relações vitais: CAUSA-EFEITO - envolve espaços mentais conectados pelas relações TEMPO (um espaço é posterior ao outro), ESPAÇO (a

${ }^{9}$ For instance a kiss could be accompanied by the sound of a car crash, of a vacuum cleaner, or of the clunking of chains, to cue metaphorical mappings of, say, disaster, dreary domestic routine, and imprisonment, respectively. 
causa e o efeito são representados no mesmo espaço físico), MUDANÇA (processo de transformação no tempo e no espaço representado como um único evento) e CAUSA-EFEITO (uma entidade ou evento é compreendido como a causa da mudança que culmina em um determinado efeito); PARTE-TODO - ocorre quando a parte de uma entidade e seu todo são projetados para o espaço-mescla, fundindo-se em uma única entidade, por exemplo, a imagem de um rosto em uma foto e a imagem de uma pessoa; PAPEL-VALOR - relação onipresente, que pode ser ativada em um espaço mental ou entre espaços mentais quando uma entidade ou valor é conectado a um papel social; ANALOGIA - depende da compressão PAPEL-VALOR, uma vez que ocorre entre entidades que compartilham o mesmo PAPEL; DESANALOGIA - é fundamentada na ANALOGIA, já que a mente humana percebe, mais facilmente, diferenças entre entidades fortemente análogas.

Conforme Grady, Oakley e Coulson (1999), as teorias da Mesclagem e da Metáfora Conceptuais podem ser consideradas complementares, porque, embora existam metáforas primárias motivadas por correlações de experiências físicas e/ou perceptuais básicas, como importância e tamanho, que, segundo a literatura, não envolvem mesclagem, tais metáforas podem configurar inputs para mesclagem. Na conceptualização das postagens da página UDD, ativam-se, de forma complementar, metáforas e mesclagens conceptuais. Na seção de análise, serão tecidas mais considerações sobre as teorias da Metáfora e da Mesclagem Conceptual.

A seguir, apresenta-se a metodologia adotada.

\section{CARACTERIZAÇÃO, PERCURSO E METAS DA PESQUISA}

A pesquisa realizada e apresentada neste artigo é considerada básica, quanto à sua natureza, pois propõe reflexões acerca dos processos conceptuais envolvidos na construção de sentidos das postagens multimodais analisadas, 
sem pretensão de aplicação prática; quanto à abordagem, caracteriza-se como um estudo qualitativo, já que se optou pela análise indutiva de apenas dois posts, sem adoção de procedimentos estatísticos; quanto aos objetivos, é caracterizada como descritiva, pois envolve coleta, observação, análise, classificação e interpretação sistemática dos objetos de estudo; quanto aos procedimentos de coleta e análise de dados, configura-se como pesquisa bibliográfica, devido à relevância de categorias de análise da Semântica Cognitiva para o estudo e à coleta das postagens multimodais publicadas na página UDD, uma fonte de pesquisa virtual.

O objetivo geral da pesquisa, como já apontado, foi identificar e descrever estruturas e processos cognitivos que subjazem à construção de sentidos das postagens multimodais acerca do posicionamento do Governo Federal diante da pandemia da COVID-19. Para tanto, as etapas do trabalho relacionam-se aos seguintes objetivos específicos:

(i) Identificação de gatilhos verbais e imagéticos que ativam metáforas monomodais e multimodais;

(ii) Descrição dos processos metafóricos monomodais e multimodais ativados a partir das postagens;

(iii) Identificação dos domínios/frames e das relações vitais envolvidos no processo de integração conceptual;

(iv) Análise do sentido emergente das mesclas, tendo em vista as fusões de elementos dos inputs e compressões de relações vitais no espaço-mescla.

Ao atingir esses objetivos, espera-se (i) contribuir com as investigações teóricas acerca de metáforas monomodais e multimodais e da complementaridade entre as teorias da Metáfora e da Integração Conceptual; (ii) identificar estruturas e relações conceptuais recorrentes na construção de sentidos das postagens multimodais, a fim de revelar a conceptualização da pandemia nos posts e o posicionamento da página UDD quanto à atuação do Governo brasileiro frente à crise sanitária; (iii) avaliar a capacidade descritiva da 
teoria da Integração Conceptual quanto ao processo de construção e interpretação do gênero post.

Os posts escolhidos como objetos de estudo foram selecionados de um corpus formado por postagens da UDD publicadas no período compreendido entre março de 2020 - quando o governador afastado do Rio de Janeiro Wilson Witzel decretou estado de emergência, dando início ao período de distanciamento social - e julho de 2020. Adotaram-se, como critérios de seleção, a temática e a constituição do post. Quanto ao primeiro critério, a escolha das postagens se justifica pela semelhança temática, que envolve ativação dos frames PANDEMIA DA COVID-19; GOVERNO BRASILEIRO e MORTE; quanto ao segundo, optouse por selecionar postagens com diferentes constituições, uma formada por legenda e texto composto por linguagem verbal e não verbal; outra, por legenda e texto não verbal, o que pode revelar o papel de gatilhos verbais e não verbais na ativação de metáforas e na construção do sentido global ativado pelos textos multimodais.

Na próxima seção, apresentam-se as análises dos textos selecionados.

\section{CONCEPTUALIZAÇÃO DE POSTS MULTIMODAIS}

Nesta seção, analisam-se dois posts multimodais coletados da página UDD no dia 5 de julho de 2020. O primeiro, intitulado "PANDEMIA DA COVID-19 NO BRASIL É FILME PÓS-APOCALÍPTICO”, foi postado no dia 21 de março de 2020; o segundo, denominado "BOLSONARO É CEIFADOR DE ALMAS", foi publicado no dia 29 de abril de 2020 .

Na primeira postagem, observam-se a legenda “Dica pra assistir nessa quarentena", a imagem do presidente Jair Bolsonaro com uma máscara hospitalar vendando seus olhos e a disposição de elementos verbais de forma a reproduzir o cartaz de lançamento do filme Bird Box na provedora global de filmes e séries de televisão Netflix. 
O post retoma uma cena da coletiva de imprensa ocorrida em 18 de março de 2020, dois dias antes da postagem, no Palácio do Planalto, da qual participaram o presidente e integrantes do primeiro escalão do Governo, incluindo o ex-ministro da Saúde Luiz Henrique Mandetta e o ministro da Economia Paulo Guedes. Durante a entrevista coletiva sobre a atuação do Governo diante da propagação dos casos de infecção pelo novo coronavírus no país, Bolsonaro contrariou recomendações de infectologistas quanto ao uso da máscara hospitalar como equipamento individual de proteção e protagonizou uma cena embaraçosa em que seus olhos ficaram vendados devido à má colocação do equipamento de proteção. Essa cena resultou em uma enxurrada de memes, por meio dos quais internautas brasileiros criticaram as ações do presidente em relação à crise sanitária atravessada pelo país.

Na Fig. 1, apresenta-se o post em que essa cena da coletiva de imprensa é integrada a elementos do cartaz de lançamento do filme Bird Box.

Fig. 1 - Post PANDEMIA DA COVID-19 NO BRASIL É FILME PÓS-APOCALÍPTICO

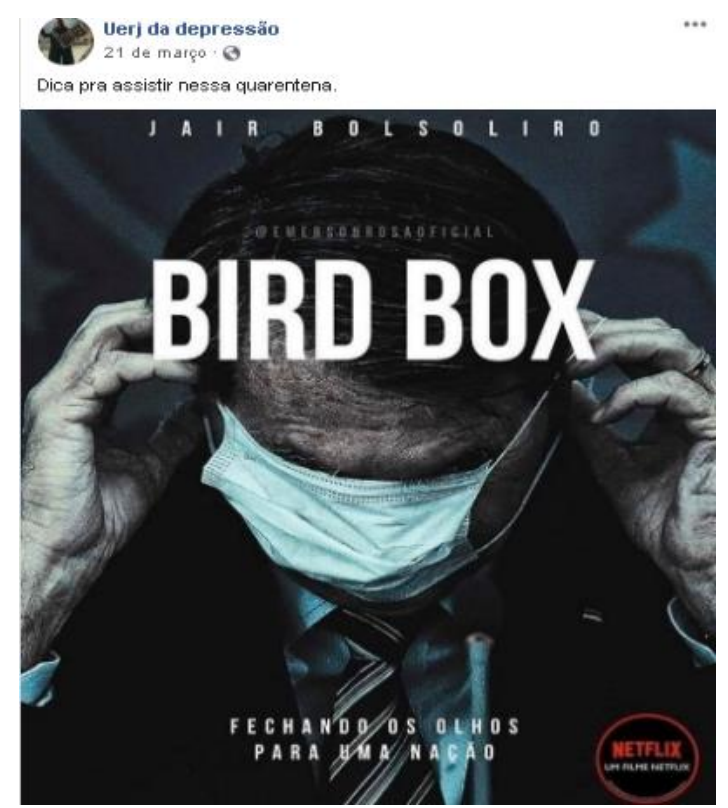

Fonte: UDD. Acesso em: 05 jul. 202010

${ }^{10}$ Disponível em: https://www.facebook.com/uerjdadepressao. Acesso em: 5 jul. 2020. 
Na construção do post, a integração da cena da coletiva a conhecimentos relacionados ao filme Bird Box foi possibilitada pela semelhança perceptual entre a máscara hospitalar utilizada por Bolsonaro e a venda usada pela personagem principal do filme, tendo em vista a identificação entre a materialidade e, sobretudo, a posição desses elementos, conforme se observa a partir da comparação do post com a Fig. 2.

Fig. 2 - Cartaz de lançamento do filme Bird Box na Netflix

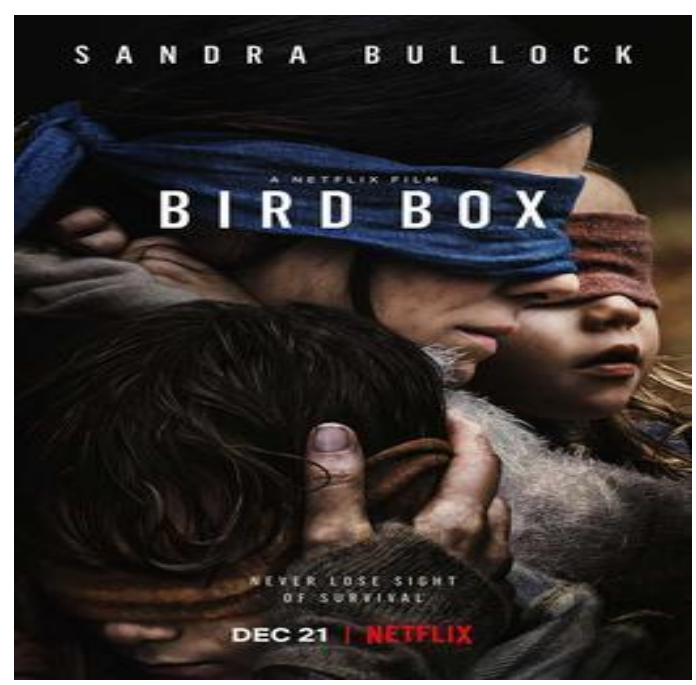

Fonte: Wikipedia. Acesso em: 05 jul. $2020^{11}$

Bird Box é uma produção americana protagonizada pela atriz Sandra Bullock e lançada em 2018 que atingiu milhões de espectadores. A produção é classificada como filme thriller pós-apocalíptico, ou seja, suspense que explora a tensão e, geralmente, envolve vítimas inocentes lidando com adversários insanos. No filme, o adversário não pode ser visto, pois o fato de olhá-lo leva os personagens a cometer suicídio.

Na Fig. 3, apresenta-se uma proposta de descrição em rede de mesclagem da conceptualização do post.

${ }^{11}$ Disponível em: https://pt.wikipedia.org/wiki/Bird_Box_(filme). Acesso em: 5 jul. 2020. 
Fig. 3 - Mesclagem PANDEMIA DA COVID-19 NO BRASIL É FILME PÓS-APOCALÍPTICO ${ }^{12}$

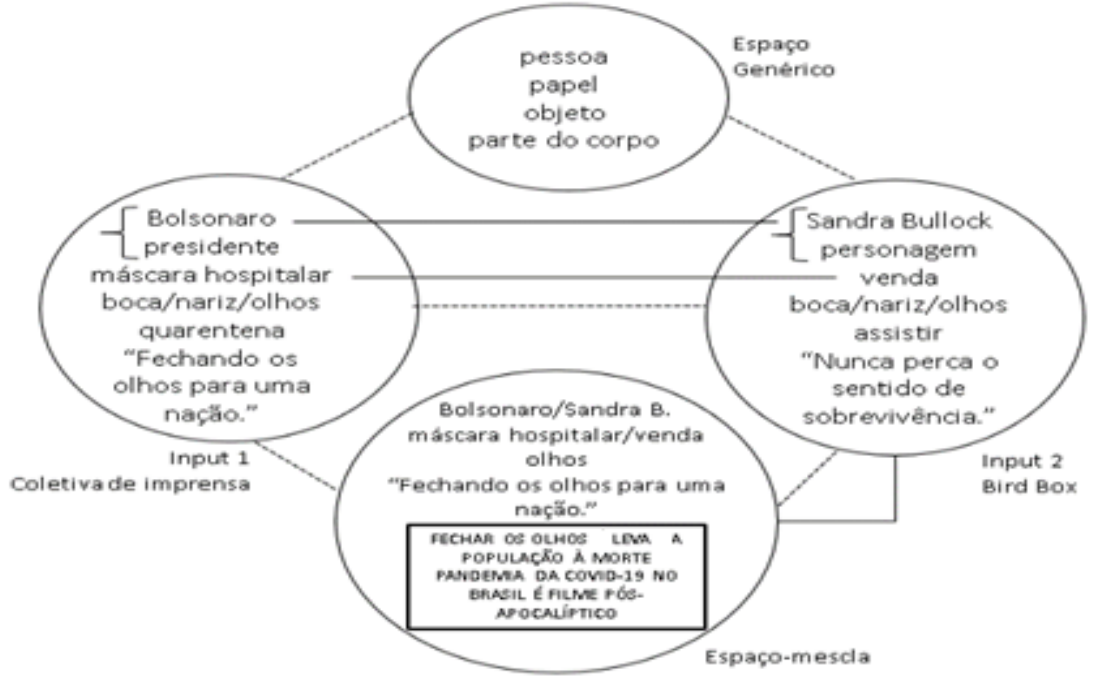

Fonte: Autores

Na Fig. 3, o input 1 é estruturado pelo frame da coletiva de imprensa realizada com o atual Governo brasileiro no contexto da pandemia da COVID19, acionado por meio da imagem de Bolsonaro com a cabeça reclinada ajeitando a máscara hospitalar que cobre seus olhos. No post, os elementos que atuam como gatilhos para a ativação de conceitos relacionados ao input 1 são o item lexical "quarentena", disposto na legenda; a construção "Fechando os olhos para uma nação", no texto postado; e as imagens de "Bolsonaro", da "máscara hospitalar" e de partes do rosto, como "boca", "nariz" e "olhos", que ganham saliência em função do uso indevido da máscara. No diagrama, também se representou o conceito de "presidente", tendo em vista o papel que Bolsonaro exerce.

O input 2, fundamentado pelo frame do filme Bird Box, é acessado pelos gatilhos verbais "assistir", que integra a legenda, "Bird Box" e "Netflix", que compõem o texto postado. Tendo em vista que o post é construído a partir do conhecimento acerca do filme e da estrutura do cartaz de seu lançamento na Netflix, representou-se, no diagrama, os elementos "Sandra Bullock" - nome da atriz que protagonizou o filme -, "personagem", “venda”, “boca”, "nariz" e

${ }^{12}$ Optou-se por não representar as projeções parciais de elementos dos inputs para a mescla, a fim de não poluir visualmente o diagrama. 
“olhos", além da construção expressa no cartaz original "Nunca perca o sentido de sobrevivência"13.

A relação vital PAPEL-VALOR atua em ambos os inputs, o que é sinalizado pelo uso de chaves no diagrama. Assim, no input 1, Bolsonaro é um VALOR para o PAPEL presidente; no input 2, Sandra Bullock é um VALOR para o PAPEL personagem.

Entre os inputs, ocorre projeção analógica entre os elementos "Bolsonaro" e "Sandra Bullock", uma vez que ambos estão vendados; e entre "máscara hospitalar" e "venda", em razão do posicionamento dos objetos sobre os olhos, construindo-se a metáfora monomodal - do tipo OBJETO A É OBJETO B - MÁSCARA HOSPITALAR É VENDA.

As projeções entre os inputs são possibilitadas pelo espaço genérico, em que se representam conhecimentos básicos comuns aos elementos dos inputs. Nesse caso, os elementos são PESSOA, PAPEL, OBJETO e PARTE DO CORPO. É esse espaço que permite a ativação simultânea de todos os espaços que compõem a rede e o acesso ou retorno a cada um deles a qualquer momento do processamento da informação.

Para o espaço-mescla, projetam-se, seletivamente, elementos de ambos os inputs. Do input 1, projetam-se "Bolsonaro", "presidente", "máscara hospitalar", "olhos" e a construção "Fechando os olhos para uma nação". Do input 2, projetam-se "Sandra Bullock", "personagem", "venda" e "olhos". Na mescla, a relação PAPEL-VALOR entre os elementos "Bolsonaro" e "presidente" e entre "Sandra Bullock" e "personagem" comprimem-se nos valores "Bolsonaro" e "Sandra Bullock", e as relações de ANALOGIA entre "Bolsonaro" e "Sandra Bullock" e entre "máscara hospitalar" e "venda" comprimem-se em UNICIDADE.

Assim, na mescla, a máscara hospitalar é a venda e o presidente Bolsonaro é a personagem principal do filme Bird Box. Entre a mescla e o input 2 há uma

${ }^{13}$ No original, “Never lose sight of survival”. 
relação de DESANALOGIA (representada, no diagrama, pelas linhas contínuas em 'L'), pois, enquanto, no input 2, vendar os olhos implica sobreviver; na mescla, fechar os olhos é ignorar as consequências extremas da propagação do novo coronavírus no Brasil. Assim, dessa rede de integração conceptual de escopo duplo - rede cujo espaço-mescla é constituído por ambos os frames organizacionais herdados dos inputs - emergem os novos sentidos FECHAR OS OLHOS LEVA A POPULAÇÃO À MORTE, por meio da compressão CAUSA-EFEITO e da DESANALOGIA com o input 2, e PANDEMIA DA COVID-19 NO BRASIL É FILME PÓsAPOCALÍPTICO, como crítica à postura do presidente frente à pandemia.

O segundo post selecionado difere-se do primeiro por ser constituído por legenda e texto composto unicamente de elementos imagéticos. Nele, observamse a legenda "Uma imagem diz mais do que textão. Créditos: Folha de SP" e a imagem do presidente Jair Bolsonaro com uma máscara hospitalar sobre nariz e boca, de túnica preta, segurando uma foice, como se observa na Fig. 4.

A criação do post apresentado na Fig. 4 foi possibilitada pelo que Forceville (2006) denomina preenchimento de slot esquemático, a partir da projeção inesperada da imagem do rosto do presidente Jair Bolsonaro usando a máscara hospitalar na imagem da entidade folclórica ceifador de almas, como sugere a Fig. 5.

Figs. 4 e 5 - Posts BOLSONARO É CEIFADOR DE ALMAS e O ceifador de almas

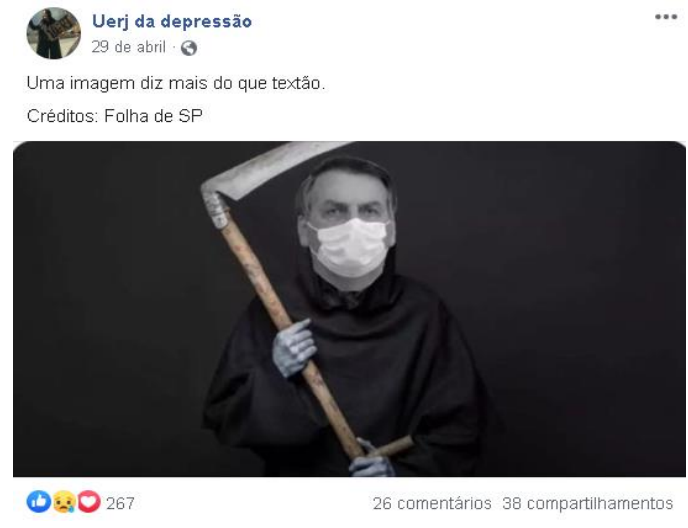

Fonte: UDD $(05 / 07 / 2020)^{14}$

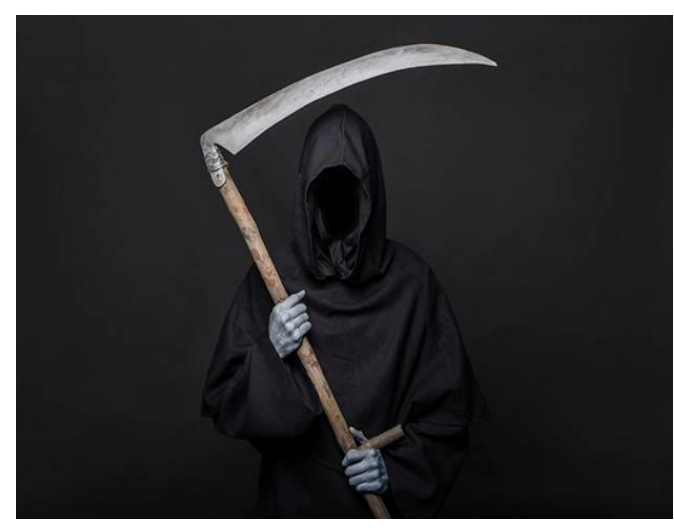

Fonte: Superinteressante $(06 / 05 / 2016)^{15}$

${ }^{14}$ Disponível em: https://www.facebook.com/uerjdadepressao. Acesso em: 5 jul. 2020.

${ }^{15}$ Disponível em: https://super.abril.com.br/blog/oraculo/qual-a-origem-da-figura-da-morte/. Acesso em: 5 jul. 2020. 
Diferentes culturas personificam a morte como um ser tenebroso conhecido como ceifador de almas ou ceifador da morte. No folclore celta, o ceifador ou "guia de almas" possui fisionomia esquelética e usa uma capa preta, que simboliza o luto.

A conceptualização desse personagem parte da personificação da morte, da metáfora conceptual PESSOAS SÃO PLANTAS e da ativação dos domínios MORTE e COLHEITA. Tendo em vista o PAPEL ceifador, trabalhador que atua na poda de cereais utilizando uma foice como instrumento para cortá-los, e a ANALOGIA entre pessoas e plantas, o ceifador de almas é aquele que abate pessoas, retirando-lhes a vida como ocorre com a planta retirada do solo. Esse produto da integração conceptual é tão enraizado em algumas culturas que uma das acepções do termo ceifador encontrada no Dicionário Online de Português ${ }^{16}$ é "quem mata, destrói ou retira a vida de outra pessoa".

Na Fig. 6, apresenta-se uma proposta de descrição em rede de mesclagem da conceptualização do post inspirado na imagem do ceifador de almas.

Fig. 6 - Mesclagem BOLSONARO É CEIFADOR DE ALMAS

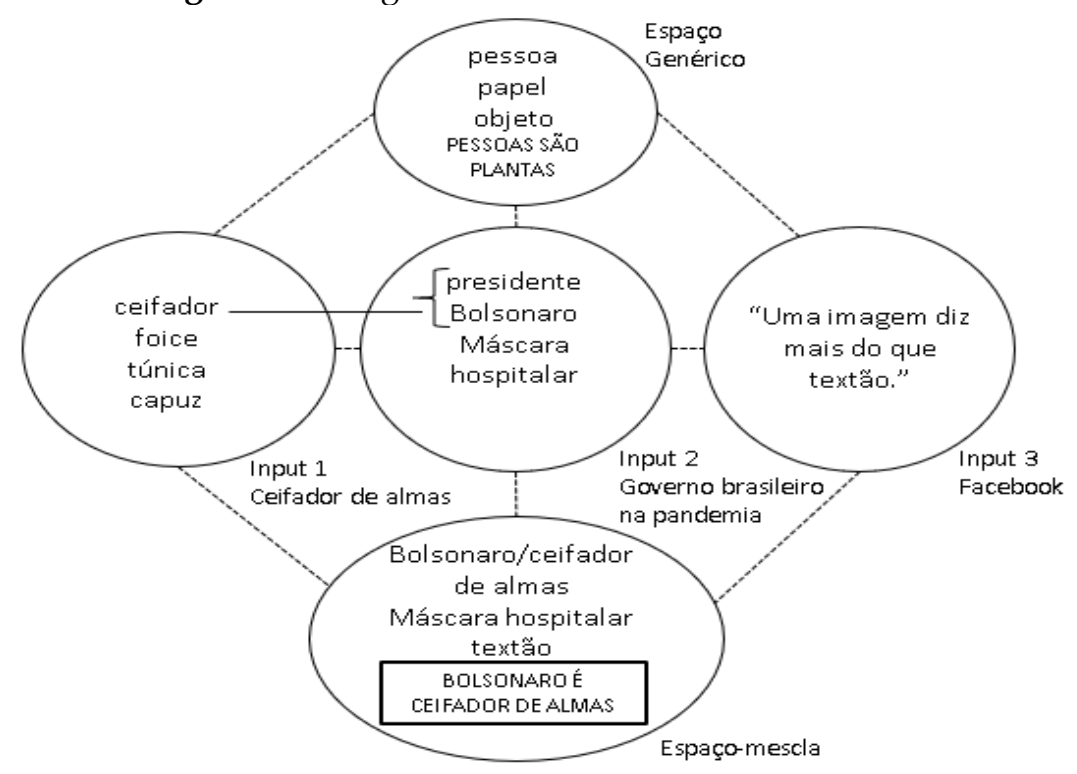

Fonte: Autores

Na Fig. 6, o input 1, composto pelos elementos 'ceifador', 'foice', 'túnica' e 'capuz', é estruturado pelo frame do ceifador de almas, acessado por meio de

${ }^{16}$ Disponível em: https://www.dicio.com.br/ceifador/. Acesso em: 5 jul. 2020. 
gatilhos pictóricos como a túnica preta, as mãos arroxeadas e a foice. A relação de PROPRIEDADE é ativada nesse espaço; assim, a foice e a túnica são conceptualizadas como posses do ceifador de almas.

O input 2, fundamentado pelo frame de Governo Brasileiro na pandemia, é acessado a partir de dois gatilhos, as imagens do rosto de Bolsonaro e da máscara hospitalar. Nesse input, constituído pelos elementos 'presidente', 'Bolsonaro' e 'máscara hospitalar', ocorre uma projeção PAPEL-VALOR entre os elementos 'presidente' e 'Bolsonaro', sinalizada, no diagrama, pelo uso das chaves. Portanto, no input 2, Bolsonaro é um VALOR para o PAPEL presidente. Ocorre ainda, neste espaço mental, uma projeção metonímica PARTE PELO TODO, pois a imagem do rosto de Bolsonaro é um veículo para o acesso ao TODO, a representação do presidente Bolsonaro. Ativa-se também a relação de PROPRIEDADE; logo, a máscara hospitalar é compreendida como posse do presidente.

O input 3, acionado a partir da legenda, mais especificamente por meio do item lexical "textão", representa o conhecimento sobre a rede social Facebook e os gêneros discursivos que nela circulam. O chamado "textão", gênero discursivo de grande circulação no Facebook, é apresentado em modo verbal e considerado extenso para a dinâmica interacional na rede social. O propósito discursivo desse gênero é evidenciar um posicionamento crítico do sujeito-enunciador, nesse caso, da página UDD.

Entre os inputs 1 e 2, ocorrem projeções analógicas entre os elementos "ceifador" e "Bolsonaro", uma vez que ambos cumpririam a mesma função de guia das almas. A projeção entre os inputs é possibilitada pelos conceitos esquemáticos PESSOA, PAPEL, OBJETO e PARTE DO CORPO, ativados no espaço genérico.

Para o espaço-mescla, projetam-se, seletivamente, elementos dos três inputs. Do input 1, projeta-se a imagem do "ceifador", em que os elementos "foice" e "túnica" estão comprimidos por meio da relação de PROPRIEDADE. Do 
input 2, projeta-se o rosto de "Bolsonaro" usando a "máscara hospitalar". Na mescla, a relação PAPEL-VALOR entre os elementos "Bolsonaro" e "presidente" comprime-se no VALOR "Bolsonaro", acionado metonimicamente. Nesse espaço, o rosto do presidente Bolsonaro se funde ao corpo do ceifador de almas, por preenchimento de slot esquemático, já que o personagem folclórico não possui rosto ou é retratado pela imagem de um esqueleto.

Assim, a relação de ANALOGIA entre os elementos "ceifador" e "Bolsonaro" projetada entre os inputs 1 e 2 comprime-se em UNICIDADE na mescla, cuja estrutura emergente é a metáfora monomodal BOLSONARO É CEIFADOR DE ALMAS. Para a mescla, projeta-se ainda, do input 3, o conhecimento sobre o gênero "textão", que reforça a função crítica do post. Logo, dessa rede de integração conceptual de múltiplo escopo - que herda os frames organizacionais de mais de dois inputs -, constrói-se o sentido de que a imagem comunicaria de forma automática e autoevidente - dispensando explanações na modalidade verbal - o posicionamento crítico da página, que responsabiliza o presidente Jair Bolsonaro pelas mortes decorrentes da propagação da COVID-19; por isso, a conceptualização do presidente como a personificação da morte.

\section{CONSIDERAÇÕES FINAIS}

As análises apresentadas indicam a atuação das mesmas estruturas e processos cognitivos para a construção e a conceptualização dos posts sobre a atuação do Governo brasileiro na pandemia da COVID-19. Observa-se, nas duas redes de integração conceptual propostas, a ativação de frames relacionados ao Governo brasileiro na pandemia e à ameaça de morte em um universo fantasioso. Notam-se ainda os mesmos processos cognitivos: projeções intradominiais PAPEL-VALOR e projeções interdominiais de ANALOGIA, comprimidas em UNICIDADE na mescla, além dos mesmos conhecimentos básicos ativados no espaço genérico, PESSOA, PAPEL, OBJETO e PARTE DO CORPO. 
Os sentidos novos, produtos das mesclas, que emergem da conceptualização dos posts - FECHAR OS OLHOS LEVA A POPULAÇÃO À MORTE, PANDEMIA DA COVID-19 NO BRASIL É FILME PÓS-APOCALÍPTICO e BOLSONARO É CEIFADOR DE ALMAS - revelam o posicionamento crítico da página UDD quanto à postura do presidente frente à pandemia e evidenciam a conceptualização do Brasil como um cenário de morte, cujo causador é o presidente Jair Bolsonaro, o que corrobora a função social do humor.

O trabalho ressalta a capacidade descritiva da teoria da Integração Conceptual, que lança luz sobre o processo de construção e interpretação do gênero post, e reforça a ideia de complementaridade entre essa teoria e a teoria da Metáfora Conceptual, tendo em vista a observação dos seguintes aspectos: i) a metáfora monomodal MÁSCARA HOSPITALAR É VENDA atua como ponto de partida da construção e da conceptualização do primeiro post, por permitir a ativação simultânea dos frames da coletiva de imprensa e do filme a partir da semelhança perceptual entre os objetos venda e máscara hospitalar, em razão da materialidade e, principalmente, da posição desses elementos, confirmando um dos postulados de Forceville (2006) quanto à construção da identidade; ii) o input 1 acionado na construção e na conceptualização do segundo post é produto de uma mescla já armazenada na memória de longo prazo, denominada ceifador de almas, cuja conceptualização se apoia na metáfora conceptual PESSOAS SÃO PLANTAS; iii) como produto de ambas as mesclas, emergiram novas metáforas.

As análises também corroboram postulados de Forceville (2006) quanto à classificação de metáforas monomodais e multimodais, uma vez que tanto gatilhos verbais quanto imagéticos acionam os domínios (ou inputs) fonte e alvo da metáfora multimodal PANDEMIA DA COVID-19 NO BRASIL É FILME PÓsAPOCALÍPTICO; e somente gatilhos imagéticos ativam os domínios fonte e alvo da metáfora monomodal BOLSONARO É CEIFADOR DE ALMAS.

A partir deste artigo, é possível propor, como trabalho futuro, a investigação aprofundada do papel das legendas na significação do gênero post. 
As análises apresentadas sugerem que as legendas ancoram o discurso na situação comunicativa, por meio da criação de um ground - nos termos de Ferrari e Sweetser (2012) - comum aos interlocutores: espaço real ou base, constituído pelo(s) gerenciador(es) da página e seus seguidores no tempo em que o discurso se desenvolve; espaços epistêmicos dos participantes da interação, que compreendem crenças e estados ou processos mentais desses participantes; espaço de ato de fala, que envolve as ações desenvolvidas por meio da linguagem, por exemplo, a crítica; espaço metalinguístico, composto de formas linguísticas potencialmente compartilhadas, como "quarentena" e "textão", e espaço metatextual, que abarca a estrutura e o histórico das interações na página.

\section{REFERÊNCIAS}

CEIFADOR. Dicionário Online de Português. Disponível em: https://www.dicio.com.br/ceifador/. Acesso em: 05 jul. 2020.

EVANS, V.; GREEN, M. Categorisation and idealised cognitive models. Cognitive Linguistics: an introduction. Edinburgh: Edinburgh University Press, 2006. p. 248-285.

FAUCONNIER, G. Mappings in thought and language. Cambridge: Cambridge University Press, 1997.

FAUCONNIER, G.; TURNER, M. The way we think: conceptual blending and the mind's hidden complexities. New York: Basis Books, 2002.

FERRARI, L.; SWEETSER, E. Subjectivity and upwards projection in mental space structure. In: DANCYGIER, B.; SWEETSER, E. (eds.). Viewpoint in language: a multimodal perspective. Cambridge: Cambridge University Press, 2012. p. 47-68.

FILLMORE, C. Frame semantics. In: GEERAERTS, D. (ed.). Cognitive linguistics: basic readings. Berlin/New York: Mouton de Gruyter, 2006. p. 373-400.

FORCEVILLE, C. Metaphor in pictures and multimodal representations. In: RAYMOND, G. (ed.). The Cambridge handbook of metaphor and thought. Cambridge: Cambridge University Press, 2008. p. 462-482.

FORCEVILLE, C. Non-verbal and multimodal metaphor in a cognitivist framework: agendas for research. In: KRISTIANSEN, G.; ACHARD, M.; DIRVEN, R.; IBÀÑEZ, F. (eds.). Cognitive Linguistics: current applications and future perspectives. Berlin/New York: Mouton de Gruyter, 2006. p. 379-402.

FORCEVILLE, C. Visual and multimodal metaphor in advertising: cultural perspectives. Styles of Communication. Amsterdam, v. 9, n. 2, p. 26-41, 2017. 
GIBBS; R.; COLSTON, H. The cognitive psychological reality of image schemas and their transformations. In: GEERAERTS, D. (ed.). Cognitive linguistic: basic readings. Berlin/New York: Mouton de Gruyter, 2006. p. 239-268.

GRADY, J.; OAKLEY, T.; COULSON, S. Blending and metaphor. In: GIBBS, R.; STEEN, G. (eds.). Metaphor in Cognitive Linguistics. Amsterdam: John Benjamins, 1999. p. 101-124.

LAKOFF, G. Women, fire and dangerous things. Chicago: University of Chicago Press, 1987.

LAKOFF, G.; JOHNSON, M. Metáforas da vida cotidiana. Tradução por Vera Maluf. Mercado de Letras: São Paulo: EDUC, 2002 [1980].

BIRD BOX. In: WIKIPÉDIA: a enciclopédia livre. Wikimedia, 2020. Disponível em: https://pt.wikipedia.org/wiki/Bird_Box_(filme). Acesso em: 05 jul. 2020.

ORÁCULO. Qual a origem da figura da morte? Superinteressante, 2016. Disponível em: https://super.abril.com.br/blog/oraculo/qual-a-origem-da-figura-da-morte/. Acesso em: 30 ago. 2020.

Nota do editor:

Artigo submetido para avaliação em: 20 de setembro de 2020.

Aprovado em sistema duplo cego em: 30 de janeiro de 2021. 